\title{
Optimal Sizing and Performance Evaluation of a Hybrid Renewable Energy System for an Off-Grid Power System in Northern Canada
}

\author{
Roshani Kaluthanthrige $^{1} \cdot$ Athula D. Rajapakse $^{1} \cdot$ Craig Lamothe $^{2} \cdot$ Farid Mosallat $^{3}$
}

Received: 5 August 2018 / Accepted: 25 January 2019 / Published online: 7 February 2019

(C) Springer Nature Singapore Pte Ltd. 2019

\begin{abstract}
Sole dependence on diesel energy has imposed a wide array of problems upon the operation of off-grid power systems in Northern Canada. Hybrid Renewable Energy Systems (HRES) have been vehemently emerging as a feasible alternative to the existing diesel-based generation facilities. To maximize the intended benefits, proper component selection, optimum sizing of the grid configuration and performance evaluation in the economic, environmental and reliability paradigms become decisive steps in their designing process. This paper presents a HOMER software-based gird optimization study to optimally retrofit a remote off-grid power system in Northern Canada. Topologies like Battery-Diesel, PV-Diesel and PV-Diesel-Battery were assessed under different scenarios to find the optimum retrofit for a primarily diesel-based generation facility. Results reveal the competence of PV-Diesel-Battery topology at high renewable penetration levels in achieving the envisioned benefits. Around a renewable penetration level of $21 \%$, fuel savings up to $22 \%$ is achievable along with $0-0.5 \%$ reductions in Levelized cost of electricity compared to the existing diesel-based power system. While diversifying the energy mix, the PV-Diesel-Battery topology considerably curbs the environmental degradation caused by the diesel-only operation and ensures the reliability, availability and security of the power supply.
\end{abstract}

Keywords Hybrid renewable energy systems $\cdot$ HOMER $\cdot$ Optimum sizing $\cdot$ Techno-economic analysis $\cdot$ Emission analysis

\section{Introduction}

Growing fuel prices and the adverse effects of increased carbon footprint have shifted the energy policies to favor more environmentally healthy approaches. Such energy policies have created an expansion in sustainable energy practices all around the world $[29,33]$. However, most of the Canadian off-grid power systems still rely on diesel as their primary energy resource. Socio-economic growth of these territories has been impeded by several economic, environmental and social constraints arising from the high reliance on diesel energy [2, 18,

Roshani Kaluthanthrige

peirisrd@myumanitoba.ca

1 Department of Electrical and Computer Engineering, University of Manitoba, Manitoba, Canada

2 Transmission Stations Operations \& Maintenance North Department, Manitoba Hydro, Manitoba, Canada

3 Engineering Research \& Development, Manitoba HVDC Research Centre, Manitoba, Canada
19, 29, 33]. Adverse environmental impacts caused by these carbon dependent generation facilities along with the increased energy costs pose the most immediate problems [19, 32].

Sustainable energy production is the process where the energy needs of the present is met without compromising the needs of the future. Governments have established Renewable Energy Portfolios that call for certain amount of electrical energy to be produced from renewables which are environmentally safe, abundant and naturally replenished [20]. In this context, Hybrid Renewable Energy Systems (HRES) incorporating locally available renewable energy sources and energy storage have emerged as perfect candidates to compete with the conventional fossil fuel generation $[2,4,14,24-26,28,33,36,39,40]$. High penetration of renewable energy sources is expected to reduce, optimize or replace fossil fuel generation while increasing carbon free generation capacity. Many off-grid communities have attempted to incorporate renewable energy sources like small hydro, solar, wind and biomass to their existing generation mix $[2,4,14,21,24-26,28,33,36,39,40]$. Several successfully commissioned utility scale hybrid power systems within Canada are reported in $[2,4,32]$. 
In deploying HRES, optimization of the power system configuration becomes vital for the success of the project. Determination of the optimum configuration dwells upon several factors. Among them randomized nature of renewable sources, climatic conditions, variations in load profile, nonlinear response of system components, cost of equipment, cost of resources, potential environmental risks etc. have made it a challenging task to assess and optimize the performance of HRES. There are different techniques employed throughout the academic literature for the optimization of HRES based power generation for off-grid applications. These methodologies can be categorised into probabilistic, analytical, iterative and hybrid methods as more deliberately discussed in [24, 36].

Many examples of optimization of HRES for different domains including off-grid power systems, shipboard power systems, residential nanogrids, etc. can be found in recent literature. In [22] the optimum shipboard HRES design has been realized with varying hourly loads considering five operating conditions. The impact of ship swing to the optimum design of solar penetrated HRES is discussed in [42] whereas a life cycle assessment for a HRES in Roll-on/Roll-off cargo ship is presented in [23]. Integration of HRES to residential buildings has offered an ample opportunities to enhance the energy access and to reduce the adverse effects of climate change [31, 38]. With the increasing attention given to smart grid concept, smart home nanogrids deploying HRES have come under close scrutiny [43, 44]. In [43] a novel optimization framework deploying convex programming is developed to obtain the optimal battery sizing of a smart home to maximize the economic benefits while meeting the home consumption. The use of convex programming has enabled the authors to optimize both management strategy and parameters without solely focusing on controls. The same convex programming approach has been utilized in [44] to optimally size a smart home nanogrid including a plugin electric vehicle load.

Simulation tools developed for a variety of applications facilitate rapid evaluation of design options for both off-grid and grid-connected power systems [24]. Among them, Hybrid Optimization Model for Electric Renewables (HOMER) has come under scrutiny as an effective tool. HOMER as a simulation platform appears repeatedly in academic literature confirming its competence in handling large set of variables associated with design, optimization and performance evaluation of HRES [4, 14, 24, 25, 28, 33, 36, 39, 40].

A brief review of optimization studies directly targeting Canadian off-grid diesel-based power systems is given here to support the methodology deployed in this study and to provide a source of comparison. In [4] authors have determined the optimum configuration for two hypothetical system designs subjecting an off-grid power system in Brochet, Manitoba. The optimum configuration has been determined by assessing their performance in three main criteria; "high electrical reliability, least cost and low environmental impact".
A "wind reduced-sized-diesel and battery" HRES has been recommended as a suitable retrofit to the existing diesel generating station. A grid optimization study for a wind-dieselbattery hybrid system for an off-grid community in SandyLake, Ontario can be found in [33]. Several scenarios have been covered with varying renewable fractions. Results have revealed that the increase of renewable fraction would cause the cost of electricity to increase while significantly decreasing the emission levels with respect to the existing dieselbased system. Authors in [21] presents a pre-feasibility study focusing on a stand-alone hybrid systems in ST. John's, NewFoundland. While concluding the economic infeasibility of solar energy integration into the standalone systems in ST. John's, authors emphasize that with potential future reduction in fuel cell cost, wind-diesel-battery-fuel cell systems could reach a more favorable position among the design options. In [28], an optimization study for grid configuration and dispatching has been conducted for a remote microgrid in Northern Ontario. The overall results draw a conclusion that integration of renewable generators and storage methods into the existing diesel-system with optimum dispatch order would result in a more environmentally and economically friendly electric power solution. A feasibility study conducted targeting the impact of wind-diesel hybrid power systems on remote communities of Aupaluk, Kuujjuaq and Salluit in Northern Quebec is presented in [14]. Optimization results confirms the applicability of incorporating a wind-dieselstorage based system to reduce high emission and cost factors associated with the current diesel-based stations. These studies have evaluated economic performance in terms of Net Present Cost (NPC) or the Levelized Cost of Electricity (LCOE), and do not point a clear conclusion on the general economic feasibility of HRES in Canada. Therefore, further technoeconomic studies would help better understand the viability of supplying isolated communities using HRES. Almost all published studies have assumed zero load growth and constant diesel price over the project life, and in coming to these conclusions, used a pre-selected energy storage type.

The objective of this study is to determine the optimum power system configuration for a typical remote off-grid community in Northern Canada while incorporating diesel, photovoltaic and battery energy storage as candidate energy options. HOMER energy platform is used as the preferred simulation tool. The optimization process was carried out for several HRES scenarios with varying levels of renewable penetration. The performance of the optimized configurations was evaluated and compared with the existing power system performance in terms of economic feasibility, reliability and environmental aspects.

The contributions of this paper primarily arise from the nature of the selected study site as well as the conducted study approach. The considered off-grid settlement in Northern Manitoba is completely isolated and land access is possible 
Fig. 1 Daily load profile

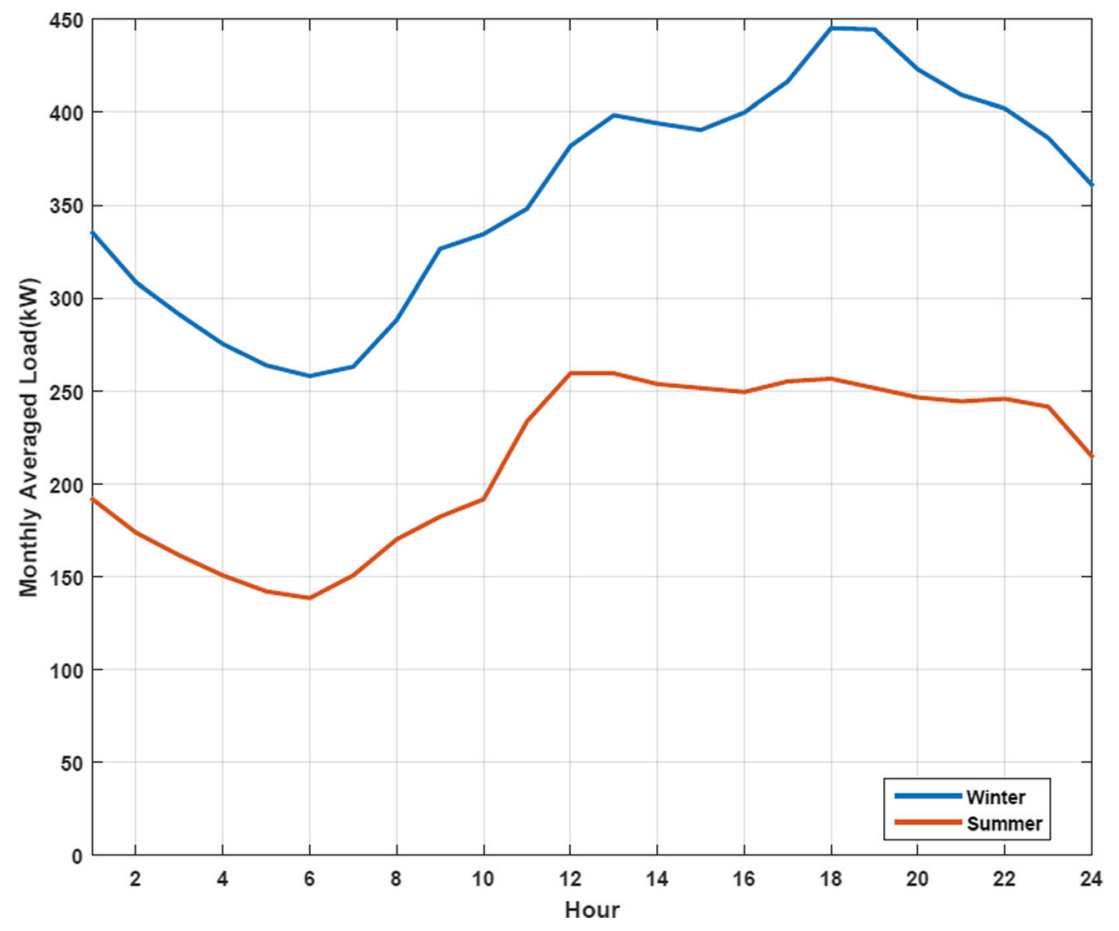

only via winter roads and limited to a few months in the year. The location experience sub-zero temperatures for most part of the year, and therefore reliability and availability of power supply is critical to the survival of inhabitants. The reliability requirement introduces constraints such as the minimum number of diesel units while weather and accessibility constraints limit the technology options for energy storage. So, the study incorporates unique site-specific characteristics. Also, in this study, HOMER Multiyear module [13] was appropriately configured to account for the variations in load and fuel prices over the project lifetime, distinguishing from most previous studies. Additionally, a preliminary battery selection process was applied to find the best battery technology to suit the sitespecific weather and accessibility constraints. Finally, economic analysis included additional indices such as Internal Rate of Return (IRR) and Return on Investment (ROI) in addition to the traditionally used Net Present Cost (NPC) or the Levelized Cost of Electricity (LCOE).

The rest of the paper is organised as follows. "Load and Resource Assessment" section presents the site background and resource assessments. "System Set-Up and Modelling" section describes the conducted system modelling procedures and system setup. "Optimization and Assessment" section presents implemented optimization methodology and adopted
Fig. 2 Global solar irradiation level

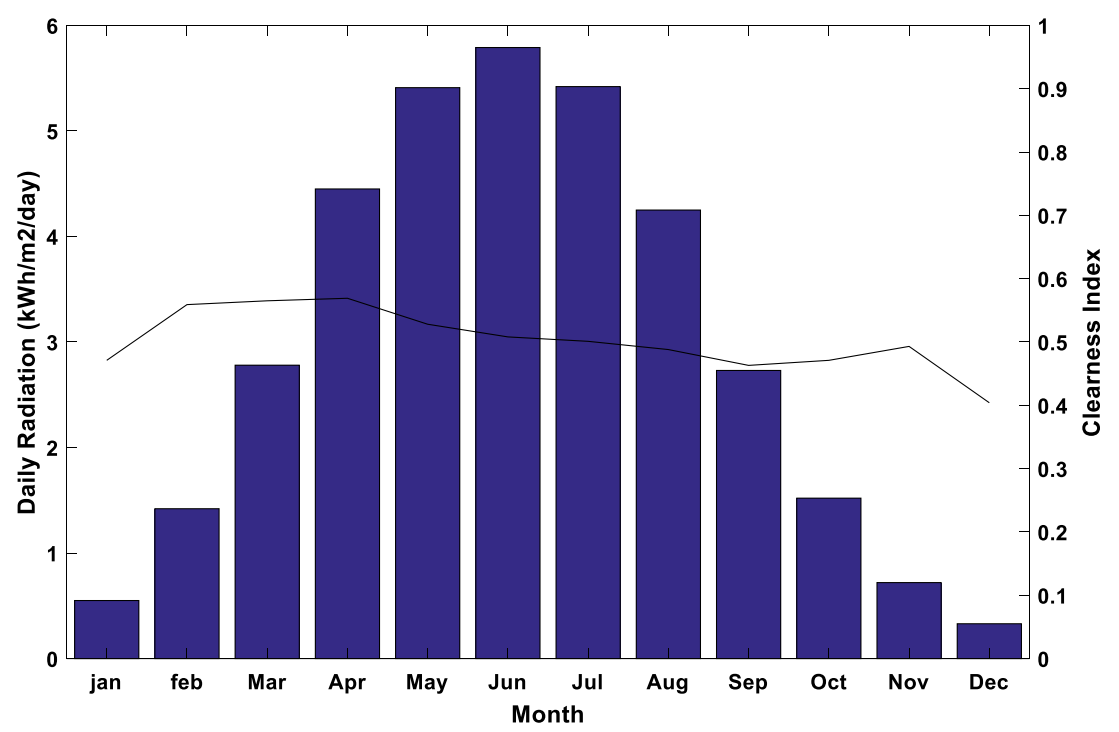


Table 1 Generator fuel consumption data

\begin{tabular}{lll}
\hline Generator $(\mathrm{kW})$ & $F_{0}\left(\mathrm{~L} / \mathrm{h} / \mathrm{kW}_{\text {rated }}\right)$ & $F_{I}\left(\mathrm{~L} / \mathrm{h} / \mathrm{kW}_{\text {output }}\right)$ \\
\hline 800 & 0.0263 & 0.2141 \\
400 & 0.0271 & 0.2439 \\
\hline
\end{tabular}

assessment criteria. "Results and Discussion" section presents the results and discussion whereas "Conclusion" section concludes the paper.

\section{Load and Resource Assessment}

\section{Site Background}

The off-grid community considered in this study is located in Northern Manitoba. In this region the annual average temperature falls below $-5{ }^{\circ} \mathrm{C}$. This remote community is only accessible using small aircrafts, except when the winter roads are in operation. As the winter roads operate only for one or two months in a year, supplies for the entire year is transported and stored during this period. The electrical power system incorporates a standalone diesel generating facility isolated from the transmission grid. To ensure high reliability, million of litres of diesel are being shipped to these Northern communities every year $[5,26]$. Transportation of diesel is mostly done over winter roads which is costly and hazardous to both people and environment. Moreover, diesel storage facilities deployed in these settlements are susceptible to fuel tank leaks which can cause significant environmental damage by contaminating soil and groundwater. The highest impact to the environment is caused through the burning of large amount of diesel which contributes significantly to greenhouse gas emissions [4, 18].

Due to several implications associated with diesel based electric production, the energy requirement of this off-grid power system often gets compromised and most of the time gets subjected to electric load restrictions. Power supply is often limited to lighting and appliances minimising the options for space heating [4, 26]. Moreover, emergencies like interruptions to the diesel supply chains and unexpected blackouts can increase energy insecurity while risking the survival of the whole community, especially during extreme cold weather conditions that constantly prevails in the Northern parts of Canada [4].

Extension of grid transmission lines can be one energy alternative. Typically, the transmission and distribution upgrades are available in larger capacity increments and undertaking such massive construction would be cost prohibitive in relation to the prevailing lower demand, high-priced man power, rugged terrain and harsh weather conditions. Also, eventual replacement of the diesel stations through grid energy obtained via long transmission lines could provide energy needs of these communities. But it would come with increased losses and reduced reliability [4, 33].

\section{Electrical Load Analysis}

The load profile of this power system was constructed after carefully monitoring actual power generation $\log$ data as well as the seasonal and diurnal variations prevailing in the Northern off-grid power systems. This approach allows the users to accurately capture the load variations including the effects of losses. Winter season depicts an elevated demand in comparison to summer. The daily energy demand is higher in the evening with respect to the morning hours. The constructed load profiles for the winter and summer seasons are given in Fig. 1.

The annual demand of this community is around $2600 \mathrm{MWh}$ and the average load is around $300 \mathrm{~kW}$. With respect to a conducted cumulative load analysis, $60 \%$ of the load lies within the $100-300 \mathrm{~kW}$ region for the base year. The electric load profiles give no traces on the exiting heating/cooling loads due to the prevailing restrictions to use electricity for space heating/cooling applications. Often, this energy requirement is

Table 2 Elementary indexes for "Efficiency"

\begin{tabular}{|c|c|c|c|c|c|c|c|c|c|}
\hline & VLA & VRLA & $\mathrm{NiCd}$ & $\mathrm{NaS}$ & $\begin{array}{l}\mathrm{Li}- \\
\text { ion }\end{array}$ & VRB & $\mathrm{Na}-\mathrm{NiCl}$ & Total & $\%$ \\
\hline VLA & & 0.5 & 0.5 & 0 & 0 & 0.5 & 0 & 1.5 & 25 \\
\hline VRLA & 0.5 & & 0.5 & 0 & 0 & 0.5 & 0 & 1.5 & 25 \\
\hline $\mathrm{NiCd}$ & 0.5 & 0.5 & & 0 & 0 & 0.5 & 0 & 1.5 & 25 \\
\hline $\mathrm{NaS}$ & 1 & 1 & 1 & & 0 & 1 & 0 & 4 & 67 \\
\hline Li-ion & 1 & 1 & 1 & 1 & & 1 & 1 & 6 & 100 \\
\hline VRB & 0.5 & 0.5 & 0.5 & 0 & 0 & & 0 & 1.5 & 25 \\
\hline $\mathrm{Na}-\mathrm{NiCl}$ & 1 & 1 & 1 & 1 & 0 & 1 & & 5 & 83 \\
\hline
\end{tabular}


Table 3 Weighting factors

\begin{tabular}{ll}
\hline Weighting factor $(\%)$ & Selection criteria \\
\hline 10 & efficiency, temperature tolerance, cycling lifetime, cost, \\
& operational flexibility, maintenance requirements, faster response \\
& environmental impact, calendar lifetime \\
7.5 & energy density, self-discharge rate \\
5 & weight, commercial availability and maturity \\
\hline
\end{tabular}

met either through wooden or oil furnaces [4]. So, assuming no change in supply current projections for annual load growth was assumed to be around $2 \%$ for this community [26].

\section{Resource Analysis}

The subjected community is gifted in several ways to optimally retrofit the diesel generation facility using renewable energy solutions such as solar, wind, bio-mass, bio-diesel and hydro. To have a precipitated advancement in carbon-free generation capacity a renewable energy option with relatively low capital cost and small regulatory as well as construction timeframe is necessary. However, several constraints have made some of these renewable sources to be opted out in the preliminary screening stages. Small hydro projects normally take up to 3-4 years to be operable in these regions and showcases high capital cost. Irrespective of the existing high wind regime, these rugged terrains offer high resistance to the transportation of wind turbine blades and has a construction period of nearly 1-2 years [26]. Bio-mass based thermal generation was opted out due to challenges associated with maintenance and insufficient local feedstocks. In addition, due to the conserved nature of this Northern settlement, a local bio-mass extraction in a higher scale could cause high social resistance. Bio-diesel based energy production also showcased few challenges to be implemented in these territories. The prevailing cold weather conditions and the inherent physical characteristics of biodiesel prohibits the use of higher blends and increases the degradation of fuel in long-term storage. Furthermore, the lack of skilled manpower has adversely affected the abovementioned renewable energy projects.

However, with less idle capacity along with relatively low maintenance and ease of capacity addition, solar photovoltaic based power production emerged as a better energy solution for this remote territory. Solar irradiance data was obtained through the NASA surface meteorology and solar energy database. The monthly averaged daily global solar irradiation levels for this site is shown in Fig. 2 along with the average clearness index for each month. The annual average daily ground horizontal irradiance for this site was estimated to be around $3 \mathrm{kWh} / \mathrm{m}^{2}$ / day. With the prevailing low ambient temperature levels and high irradiance levels, this site would be substantially good for solar power generation; specially in summer.

\section{System Set-Up and Modelling}

\section{Equipment}

\section{Diesel Generators}

The diesel generators were modelled with a minimum load ratio of $30 \%$ of the rated capacity. In a diesel generator, the amount of fuel consumed to produce electric power can be deduced by its fuel curve. So, the fuel curve of each generator
Fig. 3 Overall performance indexes as found from the preliminary battery selection process

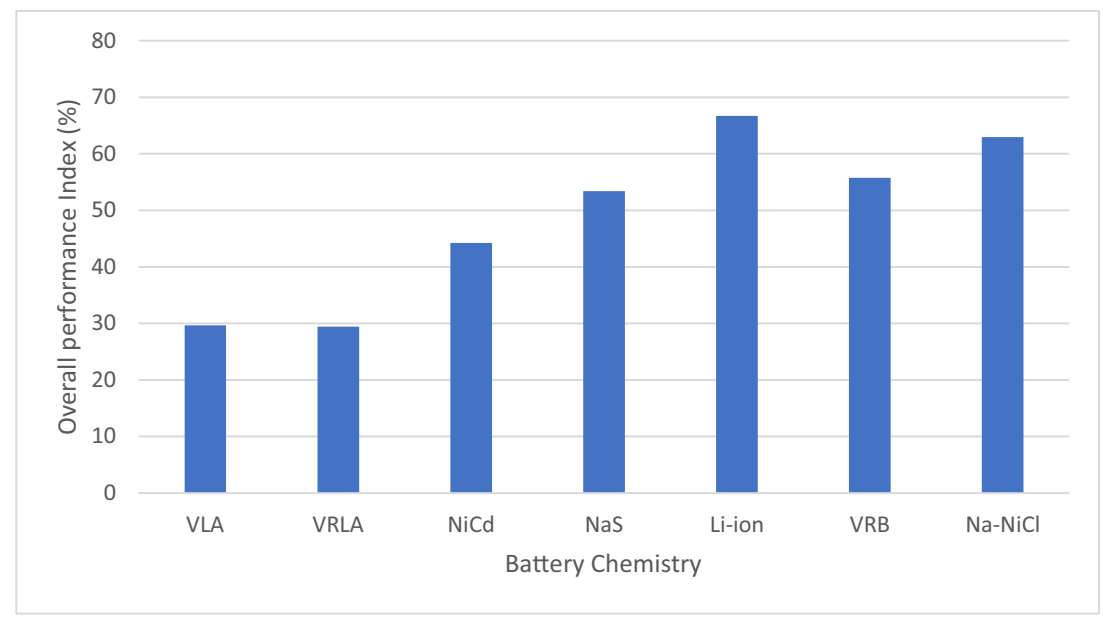


Table 4 Battery specifications

\begin{tabular}{ll} 
Chemistry & Li-ion \\
\hline Nominal Voltage (V) & 80.9 \\
Nominal Capacity (kWh) & 7.6 \\
Nominal Capacity (Ah) & 94 \\
Roundtrip efficiency (\%) & 90 \\
Maximum Charge Current (A) & 47 \\
Maximum Discharge Current (A) & 47 \\
\hline
\end{tabular}

was modelled as a straight line with a y-intercept. For constant speed internal combustion generators, a straight-line fuel curve is an accurate approximation [39]. The generator fuel consumption rate was modelled using

$F=F_{0} \times Y_{\text {gen }}+F_{1} \times P_{\text {gen }}$

where $F$ is the generator fuel consumption rate in $(\mathrm{L} / \mathrm{h}), F_{0}$ is the fuel curve intercept co-efficient in (L/h/kWrated), $F_{1}$ is the fuel curve slope in (L/h/kWoutput), $Y_{\text {gen }}$ is the rated capacity of the generator $(\mathrm{kW})$ and $P_{\text {gen }}$ is the electrical output of the generator in current time step $(\mathrm{kW})$. The values of $F_{0}$ and $F_{1}$ used in the study are given in Table 1 as specified in the HOMER database. The heat recovery effect was not considered in this study. Regarding diesel fuel properties, a lower heating value of 43.2 $\mathrm{MJ} / \mathrm{kg}$ was taken. The carbon content and the sulfur content of the fuel was taken as $88 \%$ and $0.4 \%$ respectively.

\section{Solar-PV}

The PV array was modeled considering CanadianSolar modules having a nominal max power of $280 \mathrm{~W}$, as an example. CanadianSolar is a leading solar panel manufacturer in Canada and their modules have been used in many Canadian solar PV projects. It is possible to consider any other PV module in the analysis, the differences in the performance and cost would be reflected in the results. The solar collectors were assumed to be mounted at a fixed tilt and azimuth. To obtain increased amount of uniform radiation throughout the year, the tilt angle of the collectors was set to be equal to that of the local latitude $\left(58^{0}\right)$. Also, to maximize the daily solar radiation on the collectors, they were assumed to be facing the equator making the collector azimuth angle $0^{\circ}$ and thereby
Table 6 Operating reserve definition

\begin{tabular}{ll}
\hline Operating reserve component & Percentage (\%) \\
\hline Load from the current time step demand & 10 \\
Load from annual peak demand & 5 \\
Load from current time step solar Output & 40 \\
\hline
\end{tabular}

facing South [27]. A derating factor of $90 \%$ and a ground reflectance of $80 \%$ was applied. The derating factor accounts for the reduction in the rated power output caused by realworld operating conditions (i.e. soiling of the panels, wiring losses, shading, snow cover, aging etc.). Ground reflectance is the fraction of reflected solar radiation to that incident on the ground. The effect on ambient temperature on the solar PV output was also considered. To model the solar PV generation the data downloaded from the NASA surface meteorology and solar energy database was used. Based on the latitude information of the given site, HOMER introduces the clearness indexes for each time step to calculate the solar radiation incident on the PV array. The solar array output in the current time step is calculated using

$P_{p v}=Y_{p v} \times F_{p v} \times \frac{G t}{G t_{s t c}} \times\left(1+\alpha_{p\left(T c-T c_{s t c}\right)}\right)$

where $Y_{P V}$ is the rated capacity of the PV array $(\mathrm{kW}), F_{P V}$ is the $\mathrm{PV}$ derating factor (\%), Gt is the incident solar irradiance in current time step $\left(\mathrm{kW} / \mathrm{m}^{2}\right), G t_{s t c}$ is the incident solar irradiance in standard test condition $\left(1 \mathrm{~kW} / \mathrm{m}^{2}\right), \alpha_{p}$ is the temperature coefficient of power $\left(\% /{ }^{\circ} \mathrm{C}\right), T_{c}$ is the $\mathrm{PV}$ cell temperature in current time step $\left({ }^{\circ} \mathrm{C}\right)$ and $T c_{s t c}$ is the PV cell temperature in standard test conditions $\left(25^{\circ} \mathrm{C}\right)[12,27]$.

\section{Converter}

A bidirectional converter was configured to control the power flow between $\mathrm{AC}$ and DC components. Converter size was specified as the inverter capacity. The rectifier capacity was set to be $90 \%$ of the inverter capacity, allowing both inverter and rectifier to be optimized as a single decision variable. The inversion and rectification efficiencies were taken as $96 \%$ and $94 \%$ respectively [33].

Table 5 Cost of components

\begin{tabular}{lllll}
\hline & Lifetime & Capital cost & Replacement cost & O\&M cost \\
\hline Diesel generator & $90,000 \mathrm{~h}$ & $0 \mathrm{CAD} / \mathrm{kW}$ & $2500 \mathrm{CAD} / \mathrm{kW}$ & $60 \mathrm{CAD} / \mathrm{h}$ \\
Solar Array & 25 years & $6000 \mathrm{CAD} / \mathrm{kW}$ & $6000 \mathrm{CAD} / \mathrm{kW}$ & $25 \mathrm{CAD} / \mathrm{year}$ \\
Converter & 15 years & $1000 \mathrm{CAD} / \mathrm{kW}$ & $1000 \mathrm{CAD} / \mathrm{kW}$ & - \\
Battery & 30 years calendar life & $7000 \mathrm{CAD} / \mathrm{battery}$ & $7000 \mathrm{CAD} / \mathrm{battery}$ & $10 \mathrm{CAD} /$ year \\
& 6000 cycle life @ 100\% DOD & & & \\
\hline
\end{tabular}




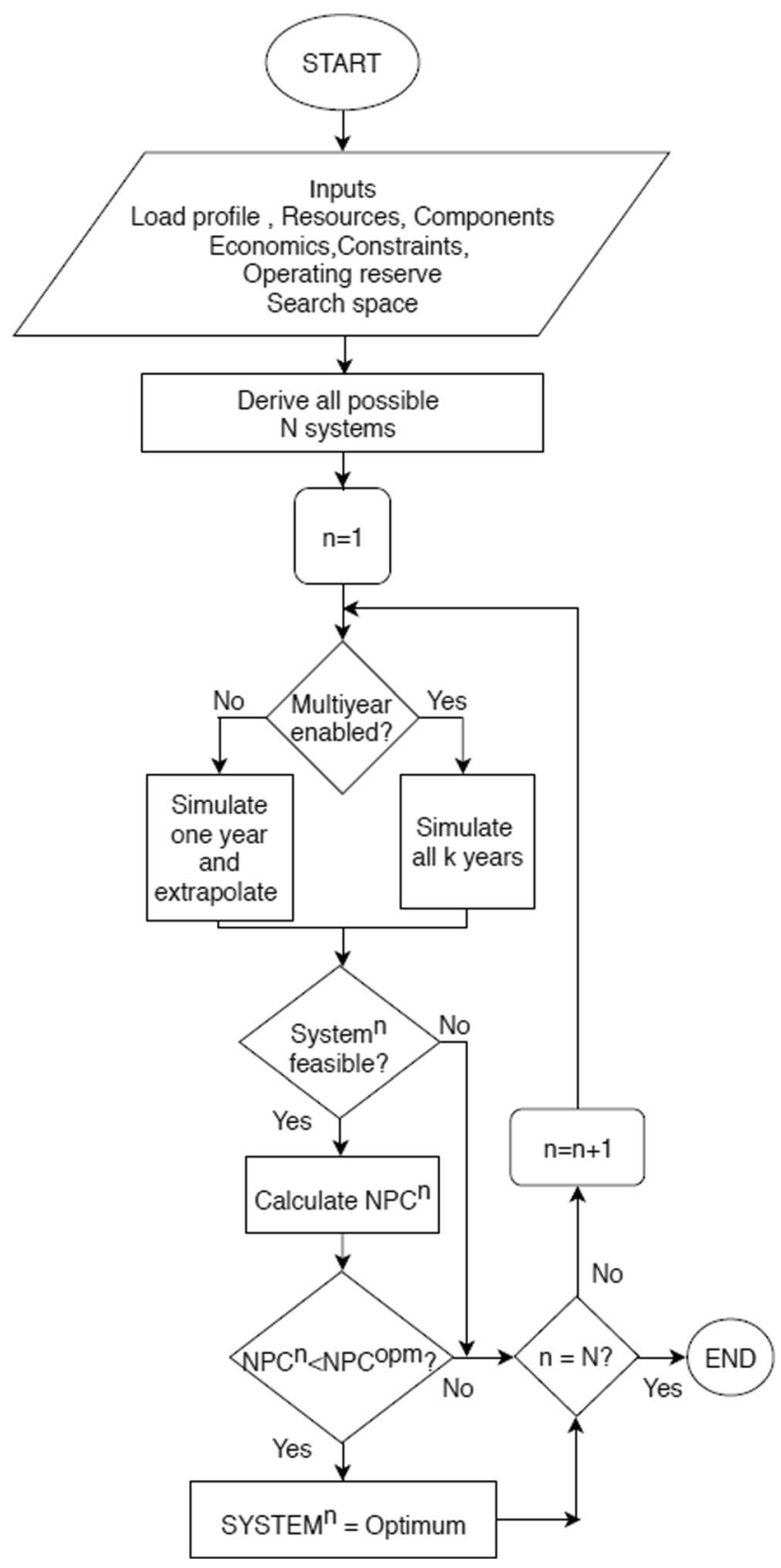

Fig. 4 HOMER optimization algorithm

\section{Battery Storage}

Among the available energy storage methods, electrochemical/ battery energy storage is the most matured and widely adopted technology for power system applications with many installations across countries [45]. The available battery storage chemistries possess different operational and business-related characteristics which glosses over a wide range of parameters. Thus, the identification of the best suited battery technology is imperative in determining the optimum power system configuration and maximizing the envisioned benefits.
A preliminary battery selection process was carried out to find the best suited technology for the Northern off-grid power system conditions following a broadly-based literature survey reviewing academic publications as well as grey literature consisting of papers and reports published by research laboratories, consultancy agencies and industry specialists. The energy storage selection method discussed in [16] was extended to seven potential battery technologies including Lead acid (Vented (VLA) and Valve Regulated (VRLA)), Nickel Cadmium (NiCd), Sodium Sulfur (NaS), Lithium ion (Li-ion), Sodium Nickle Chloride $(\mathrm{Na}-\mathrm{NiCl})$ ) and Vanadium Redox (VRB). The relative performance of the considered battery technologies was assessed under thirteen high impact battery storage selection criteria namely; (1) efficiency, (2) calendar lifetime, (3) environmental impact, (4) cost, (5) energy density, (6) selfdischarge rate, (7) cycling life, (8) operational flexibility, (9) temperature tolerance, (10) commercial availability and maturity, (11) maintenance requirements, (12) weight and (13) response time. In order to quantify the relative performance under a given criteria, an elementary index value, which indicates how well a battery technology performs relative to all the other considered technologies, is assigned. Table 2 illustrates an example assignment of elementary indices for the selection criterion "Efficiency". The performance of a battery technology in a particular row gets evaluated with respect to the battery technologies found in each column. For each comparison a value of either $0,0.5$ or 1 was assigned relative to the one it is compared with. If the associated performance is worse, " 0 " was given whereas " 0.5 " and " 1 " was allocated for equal and better performances respectively, based on the information collected from the broad-based literature survey. Thirteen similar tables were constructed considering each of the different criteria.

When evaluating the relative suitability of technologies for a given application, a weighting factor (in the range of $0-10 \%$ ) is assigned to each of the thirteen criteria, considering their importance to the considered HRES applications [1, 9]. Pertaining to the isolated placement of these settlements, inadequacy of operating and maintaining personnel and extreme cold weather conditions, the reliability and availability of the system becomes substantially important. Also, its operation must be highly efficient, and the capital and maintenance cost of the systems should be minimum to yield maximum benefits over its life cycle [35]. Thus, criteria like efficiency, temperature tolerance, cycling lifetime, cost, operational flexibility, maintenance requirements, faster response were given high weightage. The weighting factors used in this study are given in Table 3 and were mostly based on engineering judgement.

Finally, an overall performance index was defined for each candidate battery technology based on their obtained weighted average performance using [16, 17]

Overall_Index $x_{b}=\sum_{i=1}^{13}$ ElementaryIndex $_{b}{ }^{i} \times$ WeightingFactor $^{i}$ 


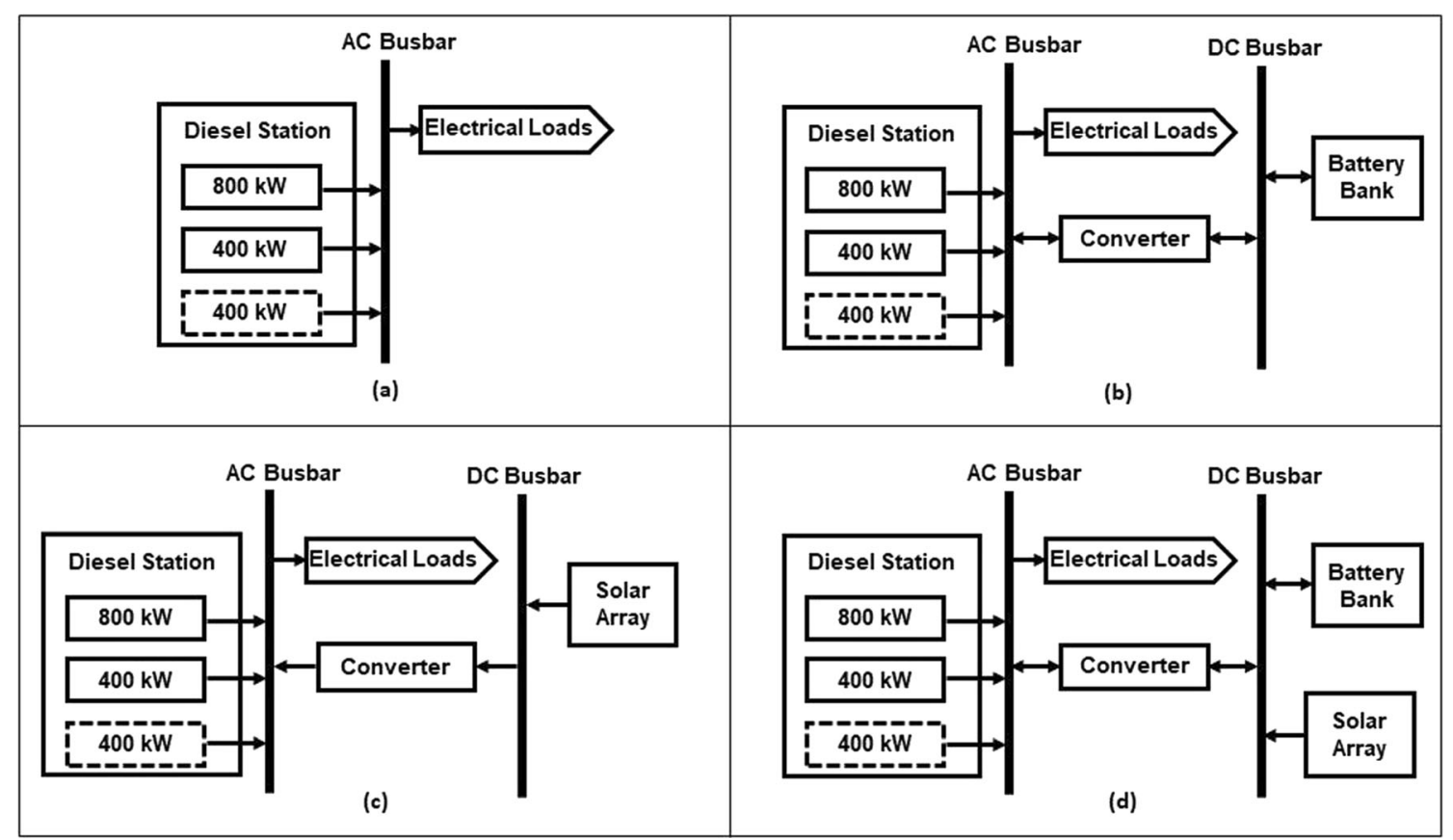

Fig. 5 Power system configurations

where Overall_Index $x_{b}$ is the overall performance index for the battery type "b", ElementaryIndex ${ }_{b}{ }^{i}$ is the elementary index of battery type " $b$ " under the $i^{\text {th }}$ criterion and WeightingFactor ${ }^{i}$ is the assigned weightage of criterion " $i$ ". Based on the overall result, Li-ion batteries showed the highest relative performance to be deployed in the hybrid power systems in the North as shown in Fig. 3.

The overall result of the preliminary battery selection can be validated through the growing body of literature highlighting the potential of Li-ion battery technology in boosting the performance of renewable energy systems [8, 11, 30, 37]. Since its commercial introduction by Sony in the early 1990s, Li-ion batteries have shown rapid advancements in high energy density, efficiency, deep cycle ability, safety and long cycle life $[8,15,30]$. Currently they are manufactured using graphite anodes and lithium metal oxide cathodes such as layered $\mathrm{LiNi}_{\mathrm{x}} \mathrm{Co}_{\mathrm{y}} \mathrm{Mn}_{\mathrm{z}} \mathrm{O}_{2}(\mathrm{NMC}), \mathrm{LiMn}_{2} \mathrm{O}_{4}, \mathrm{LiFePO}_{4}$ and $\mathrm{Li}_{4} \mathrm{Ti}_{5} \mathrm{O}_{12}$ [7]. For off-grid photovoltaic applications, high cycling life, no memory effect, lower maintenance, low selfdischarge rates and minimized operational constraints have become the figures of merit for Li-ion over the other available battery storage technologies $[7,8]$. Still, Li-ion batteries are subjected to high capital costs, which is a significant concern when deploying them in a standalone power system $[3,8]$. However, driven by research and development, the appealing features of Li-ion batteries have been improving continuously and price reductions are also expected in the future [37]. In addition, with the growth of parallel sectors like the automobile industry, researchers believe that Li-ion batteries will be more affordable due to mass production and would get fully adopted to renewable energy systems $[8,11]$.
HOMER models the battery bank as a collection of batteries that can store fixed amount of DC electricity at a fixed round trip efficiency. The control decision of supplying $\mathrm{AC}$ load and operating reserve from the storage depends on its current discharge capacity and the capacity and efficiency of the converter [10]. A method to determine the number of batteries required to coarsely initialize the search space can be found in $[25,39]$. The specifications for the selected battery are given in Table 4.

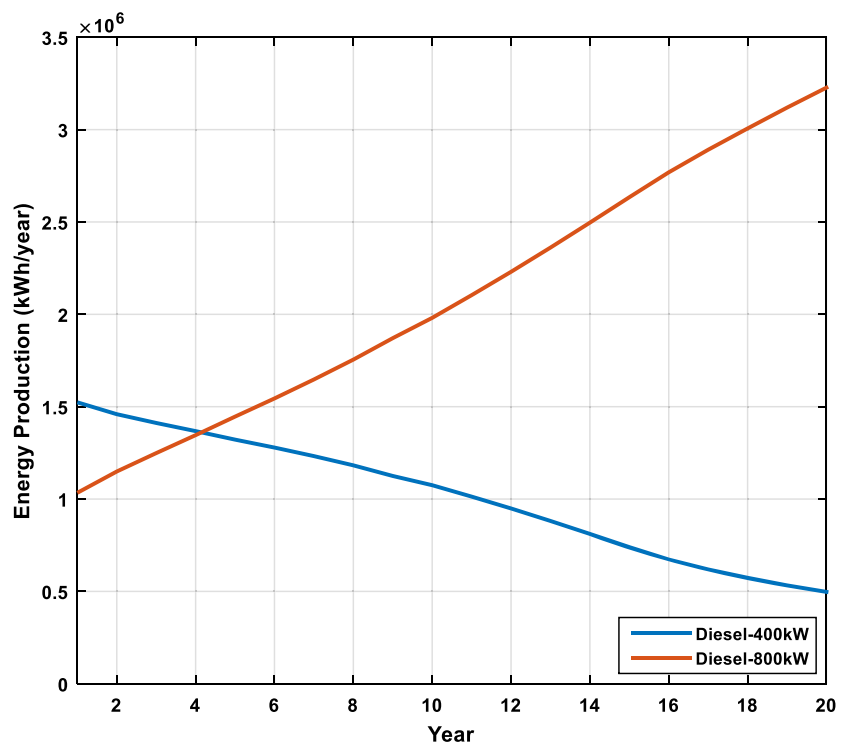

Fig. 6 Energy production for the Base case 
Table 7 Search space for Battery-Diesel case

\begin{tabular}{lll}
\hline Component & & Scenario 1 \\
\hline Diesel Generators & $800 \mathrm{~kW}$ & With or without $800 \mathrm{~kW}$ \\
& $400 \mathrm{~kW}$ & With or without $400 \mathrm{~kW}$ \\
Battery & & $10-200$ units, 10 units steps \\
Converter & $25-450 \mathrm{~kW}, 25 \mathrm{~kW}$ steps \\
\hline
\end{tabular}

\section{Project Economics}

This study uses a project lifetime of 20 years. Canadian Dollar (CAD) is used as the currency for all cost figures. A nominal discount rate of $6 \%$ and an expected inflation rate of $2 \%$ was considered $[4,26,33,41]$. The landed fuel prices in Northern remote off-grid areas are estimated to be higher than that of elsewhere in Canada. In this study landed cost of diesel was taken as $1.1 \mathrm{CAD} /$ litre subjected to a fuel price escalation rate of $1 \%[4,33]$. This is the wholesale market (rack) price inclusive of the diesel transportation costs. The federal government of Canada has proposed a carbon tax to each province that would start at $\$ 10$ a tonne in 2018 and rise to $\$ 50$ per tonne by 2022 . However, provinces like Manitoba have thoroughly opposed this carbon tax increase proposing their own flat rate. This decision was well justified through their cleaner electricity system with massive hydro power investments [6]. In this study, a penalty cost of $25 \mathrm{CAD} /$ ton was imposed on the $\mathrm{CO}_{2}$ emissions. This approach allows the GHG emissions and renewable penetration to be indirectly accounted in the optimization process.

The three main cost figures of each system component and their lifetimes can be found in Table 5. All costs were carefully determined through analysing HOMER database, contacting suppliers, reviewing contemporary academic literature and analysing industrial reports and presentations. Capital cost is the total installed cost of the component at the beginning of its lifetime. This mainly includes cost incurred for permits, purchasing, installation and labor. As the existing diesel generators require no capital investment, their capital cost was taken as zero [10, 39]. Given the remoteness of the considered site, the installation and labour costs for PV, converter and battery are significantly high compared to other parts of Canada. The replacement cost is incurred at the end of a component life time. Operation and maintenance cost accounts for the costs associated with operating and

Table 8 Optimum Battery-Diesel system estimated by HOMER

\begin{tabular}{lll}
\hline Component & & Scenario 1 \\
\hline Diesel Generators & $800 \mathrm{~kW}$ & $800 \mathrm{~kW}$ \\
& $400 \mathrm{~kW}$ & $400 \mathrm{~kW}$ \\
Battery (units) & & 10 \\
Converter (kW) & 25 \\
\hline
\end{tabular}

Table 9 Economic analysis of Battery-Diesel case

\begin{tabular}{lll}
\hline & Base Case & Battery-Diesel \\
\hline LCOE (CAD/kWh) & 0.5146 & 0.5165 \\
NPC (CAD) & $21,314,090$ & $21,393,270$ \\
ROI (\%) & - & -2.6 \\
IRR (\%) & - & $\mathrm{n} / \mathrm{a}$ \\
Simple payback time (yr) & - & $\mathrm{n} / \mathrm{a}$ \\
\hline
\end{tabular}

maintaining a specific component and excludes the fuel cost. HOMER calculates fuel cost separately.

\section{Control and Constraints}

HOMER models two main dispatch methods; load-following (LF) and cycle-charging (CC). Under cycle charging, both generators and renewable sources are committed to charge the battery bank whereas under the load following strategy only renewable sources are committed to charge the battery bank [10]. To enhance the system reliability despite the variabilities in load and supply, an operating reserve was defined as a safety margin as given in Table 6 . A constraint was used on the annual capacity shortage to eliminate the configurations with capacity shortages more than $0.01 \%$.

HOMER does not model electrical transients and other dynamic effects which requires a very small time-step. This study uses an hourly time step to adequately capture the important statistical aspects prevailing in the load and intermittent sources. This time step also serves in reducing the computational burden of the optimization task [10].

\section{Optimization and Assessment}

\section{HOMER Optimization}

HOMER uses the Net Present Cost (NPC) to represent the life cycle cost associated with the projected system operation. NPC is calculated by discounting the future cash flows into a single lump sum in year-zero. HOMER takes NPC as the basic assessment criteria in its optimization algorithm. Optimization involves the determination of the best component mix, size and quantity of each component and the preferable dispatch strategy. HOMER grid search algorithm is shown in Fig. 4 where; NPC ${ }^{n}$ is the NPC of the $n^{\text {th }}$ system and $\mathrm{NPC}^{\mathrm{opm}}$ is the NPC of the last recorded optimum system [39]. This optimization process undertakes all the possible grid configurations derived from a user-defined set of decision variable values (search space). By simulating all derived system configurations, it determines the optimum system that meets the electric loads and operating reserve while satisfying the user-specified constraints at the lowest NPC [10, 39]. 
Table 10 Search space for PVDiesel case

\begin{tabular}{|c|c|c|c|c|}
\hline Component & & Scenario 1 & Scenario 2 & Scenario 3 \\
\hline \multirow[t]{2}{*}{ Diesel Generators } & $800 \mathrm{~kW}$ & $\begin{array}{l}\text { With or without } \\
800 \mathrm{~kW}\end{array}$ & $\begin{array}{l}\text { With or without } \\
800 \mathrm{~kW}\end{array}$ & $\begin{array}{l}\text { With or without } \\
800 \mathrm{~kW}\end{array}$ \\
\hline & $400 \mathrm{~kW}$ & $\begin{array}{l}\text { With or without } \\
400 \mathrm{~kW}\end{array}$ & $\begin{array}{l}\text { With or without } \\
400 \mathrm{~kW}\end{array}$ & $\begin{array}{l}\text { With or without } \\
400 \mathrm{~kW}\end{array}$ \\
\hline \multirow{2}{*}{\multicolumn{2}{|c|}{ Solar PV }} & $25-200 \mathrm{~kW}$ & $200 \mathrm{~kW}-400 \mathrm{~kW}$ & $400 \mathrm{~kW}-700 \mathrm{~kW}$ \\
\hline & & $25 \mathrm{~kW}$ steps & $25 \mathrm{~kW}$ steps & $25 \mathrm{~kW}$ steps \\
\hline \multirow{2}{*}{\multicolumn{2}{|c|}{ Converter }} & $25-250 \mathrm{~kW}$ & $150 \mathrm{~kW}-450 \mathrm{~kW}$ & $350 \mathrm{~kW}-750 \mathrm{~kW}$ \\
\hline & & $25 \mathrm{~kW}$ steps & $25 \mathrm{~kW}$ steps & $25 \mathrm{~kW}$ steps \\
\hline \multicolumn{2}{|l|}{ Dispatch } & $\mathrm{LF}$ or $\mathrm{CC}$ & $\mathrm{LF}$ or $\mathrm{CC}$ & $\mathrm{LF}$ or $\mathrm{CC}$ \\
\hline
\end{tabular}

HOMER by default runs the simulation for the first year and then extrapolates the results over the rest of the project lifetime. However, in this study HOMER Multiyear module was used to account for the load growth and fuel price escalation. So, the simulation was carried out for every year in the project lifetime while accounting for the year by year percentage change in load and fuel price. Through this approach the important temporal variations in these parameters were incorporated in the final result improving its credibility at the cost of increased simulation time.

\section{Assessment Criteria}

\section{Economic Assessment}

The financial viability of the optimized systems will be evaluated using both intrinsic and extrinsic parameters. Intrinsic parameters like NPC and Levelized cost of electricity (LCOE) assess the project independent of other energy alternatives. LCOE is derived using Eq. 4. A more detailed description of these economic indices and their involvement in assessing distributed energy projects can be found in [27].

$L C O E=\frac{\text { Levelized annual cost }\left(\frac{C A D}{y r}\right)}{\text { Levelized annual electric load served }\left(\frac{k W h}{y r}\right)}$

Due to complexity associated with structure, longevity of operation and cash flows, the economic assessment of

Table 11 Optimum PV-Diesel systems estimated by HOMER

\begin{tabular}{lllll}
\hline Component & & Scenario 1 & Scenario 2 & Scenario 3 \\
\hline Diesel Generators & $800 \mathrm{~kW}$ & $800 \mathrm{~kW}$ & $800 \mathrm{~kW}$ & $800 \mathrm{~kW}$ \\
& $400 \mathrm{~kW}$ & $400 \mathrm{~kW}$ & $400 \mathrm{~kW}$ & $400 \mathrm{~kW}$ \\
Solar PV (kW) & 25 & 200 & 400 \\
Converter (kW) & 25 & 150 & 350 \\
Dispatch & $\mathrm{CC}$ & $\mathrm{CC}$ & $\mathrm{LF}$ \\
Renewable fraction (\%) & 0.929 & 7.76 & 14.7 \\
\hline
\end{tabular}

distributed energy projects are advised to incorporate extrinsic parameters to arrive at viable conclusions [27]. Extrinsic economic parameters like Return on Investment (ROI), Internal Rate of Return (IRR) and Simple pack back time measure the associate performance between a given system and a predefined base case system. Payback time relates to the period of time at which the cumulative cash flows of the difference between current and base system switches from a negative to a positive value. It gives a measure of time that takes to recover the investment cost in relation to a reference.

IRR is determined by calculating the discount rate for which the difference between the net present costs of the two systems become zero. ROI calculates the yearly cost savings relative to the base case system. Both IRR and ROI are proven economic measures for distributed energy projects and allows the energy investment to be directly compared with the return that might be obtained form the base-case diesel only system [27].

However, for the extrinsic economic parameters to make sense, the selected base case system should have a comparatively lower initial capital value and a higher operating cost than the selected system. Violation of this criteria would not result any answers ("N/A") in the HOMER economic comparisons.

\section{Reliability Assessment}

Unmet electric load and the capacity shortage was taken as the main criteria to assess the reliability of the optimised systems. Unmet electric load provides information on the load that went unserved due to insufficient generation. Capacity shortage is an indication of the system's inability to support the required operating capacity, including load and the userdefined operating reserve.

\section{Environmental Assessment}

Environmental assessment mainly incorporated an emission analysis. The renewable fraction of the system given by Eq. 5 was also observed. 
Table 12 Economic analysis of PV-Diesel case

\begin{tabular}{lllll}
\hline & Base Case & Scenario 1 & Scenario 2 & Scenario 3 \\
\hline LCOE (CAD/kWh) & 0.5146 & 0.5158 & 0.5235 & 0.5468 \\
NPC (CAD) & $21,314,090$ & $21,364,520$ & $21,684,360$ & $22,649,110$ \\
ROI (\%) & - & 0.4 & 0.5 & -1.1 \\
IRR (\%) & - & 1.9 & 0.9 & $\mathrm{n} / \mathrm{a}$ \\
Simple payback time $(\mathrm{yr})$ & - & 18.03 & 18.16 & 18.87 \\
\hline
\end{tabular}

Renewable fraction $=1-\frac{E_{\text {nonren }}}{E_{\text {served }}}$

Where $E_{\text {nonren }}$ is the non-renewable electrical energy production $(\mathrm{kWh})$ and $E_{\text {served }}$ is the electricity load served (kWh).

\section{Results and Discussion}

First the existing Diesel-only system was analysed and benchmarked to serve as a reference case as shown in Fig. 5a. In the study that follows, it was expected to find the best hybrid renewable retrofit for the existing power system to enhance its economic and environmental performance while maintaining a high reliability. Three hypothetical electrical system designs were investigated namely; 1) Battery-diesel, 2) PV-Diesel and 3) PV-Diesel-Battery as shown in Fig. 5b-d respectively.

\section{Base-Case Diesel-Only System}

Due to concerns regarding reliability of supply and future load growth, the diesel generators deployed in most of the dieselbased communities are oversized and the total installed capacity is much higher than the daily average load. This study uses two diesel generators ( $800 \mathrm{~kW}$ and $400 \mathrm{~kW}$ ) operating in parallel for the base case scenario. An additional $400 \mathrm{~kW}$ generator remains stand by, to be used in case one of the generators fails since the delivery of spare parts and repair crews could take time. The operation of the two diesel generators was configured in "optimized" mode in HOMER. In this mode, HOMER decides the optimum schedule of operation to obtain least cost. Results confirmed the high reliability associated with the existing system, which is an essential attribute for the energy security of these off-grid settlements. There were no capacity shortages and unmet electric loads during the project lifetime. According to Fig. 6, during the initial phase of the project most of the load demand is adequately met by the $400 \mathrm{~kW}$ generator. During this period the $800 \mathrm{~kW}$ generator will remain oversized and will be operated in lower ranges of its capacity to meet the load demand. This results in reduced efficiency and causes high fuel consumption [4]. However, this oversized scenario prevails for a small part of the project duration and as the load increases subjected to a $2 \%$ load growth, $800 \mathrm{~kW}$ generator takes over most of energy production. The mean electric efficiency is accounted to be $35.6 \%$ and $38.5 \%$ for $400 \mathrm{~kW}$ and $800 \mathrm{~kW}$ generator respectively.

Even though this system guarantees high reliability the increased reliance on diesel-based electricity production will impose several constraints on the economic and environmental performance of this power system if the diesel-only operation were to be continued in the future. This system is subjected to a high LCOE of $0.5146 \mathrm{CAD} / \mathrm{kWh}$ mainly due to the increasing price of diesel prevailing in this region. Also, the conducted environmental analysis revealed considerably high amounts of emissions associated with its operation. The conducted emission analysis will be presented and compared with other candidate configurations in the following sections.
Table 13 Search space for PVDiesel-Battery case

\begin{tabular}{|c|c|c|c|c|}
\hline Component & & Scenario 1 & Scenario 2 & Scenario 3 \\
\hline \multirow[t]{2}{*}{ Diesel Generators } & $800 \mathrm{~kW}$ & $\begin{array}{l}\text { With or without } \\
800 \mathrm{~kW}\end{array}$ & $\begin{array}{l}\text { With or without } \\
800 \mathrm{~kW}\end{array}$ & $\begin{array}{l}\text { With or without } \\
800 \mathrm{~kW}\end{array}$ \\
\hline & $400 \mathrm{~kW}$ & $\begin{array}{l}\text { With or without } \\
400 \mathrm{~kW}\end{array}$ & $\begin{array}{l}\text { With or without } \\
400 \mathrm{~kW}\end{array}$ & $\begin{array}{l}\text { With or without } \\
400 \mathrm{~kW}\end{array}$ \\
\hline \multirow{2}{*}{\multicolumn{2}{|c|}{ Solar PV }} & $0-200 \mathrm{~kW}$ & $200 \mathrm{~kW}-400 \mathrm{~kW}$ & $400 \mathrm{~kW}-700 \mathrm{~kW}$ \\
\hline & & $25 \mathrm{~kW}$ steps & $25 \mathrm{~kW}$ steps & $25 \mathrm{~kW}$ steps \\
\hline \multirow{2}{*}{\multicolumn{2}{|c|}{ Converter }} & 0-200 kW & $150 \mathrm{~kW}-450 \mathrm{~kW}$ & $350 \mathrm{~kW}-750 \mathrm{~kW}$ \\
\hline & & $25 \mathrm{~kW}$ steps & $25 \mathrm{~kW}$ steps & $25 \mathrm{~kW}$ steps \\
\hline \multirow{2}{*}{\multicolumn{2}{|c|}{ Battery }} & $0-50$ units & $0-150$ units & 0-200 units \\
\hline & & 10 units/step & 10 units/step & 10 units/step \\
\hline \multicolumn{2}{|l|}{ Dispatch } & $\mathrm{LF}$ or $\mathrm{CC}$ & LF or $\mathrm{CC}$ & $\mathrm{LF}$ or $\mathrm{CC}$ \\
\hline
\end{tabular}


Table 14 Optimum system configuration as estimated by HOMER

\begin{tabular}{lllll}
\hline Component & & Scenario 1 & Scenario 2 & Scenario 3 \\
\hline Diesel Generators & $800 \mathrm{~kW}$ & $800 \mathrm{~kW}$ & $800 \mathrm{~kW}$ & $800 \mathrm{~kW}$ \\
& $400 \mathrm{~kW}$ & $400 \mathrm{~kW}$ & $400 \mathrm{~kW}$ & $400 \mathrm{~kW}$ \\
Solar PV (kW) & 25 & 400 & 625 \\
Converter (kW) & 25 & 450 & 600 \\
Battery & 10 units & 110 units & 120 units \\
& $(76 \mathrm{kWh})$ & $(836 \mathrm{kWh})$ & $(912 \mathrm{kWh})$ \\
Dispatch & LF & CC & CC \\
Renewable fraction $(\%)$ & 0.936 & 13.4 & 20.84 \\
\hline
\end{tabular}

\section{Battery-Diesel Case}

This section assesses the viability of using battery storage to solely optimize the operation of the subjected off-grid diesel facility. HOMER optimization was carried out for the decision variables given in Table 7 and the obtained optimized system is shown in Table 8.

According to Table 8, the optimized sizes of the battery and the converter got saturated at the lower limit of the search space. So, the sole addition of batteries to the current system would certainly become a poor investment choice as suggested by the economic indices in Table 9. Considering the poor associate economic performance to the base case system, battery-diesel configuration was opted out from further analysis.

\section{PV-Diesel Case}

HOMER optimization was carried out for gradually increasing solar penetration levels under three defined scenarios. The deployed decision variables for each scenario is given in Table 10 and the obtained optimized configurations are shown in Table 11.

The optimised systems were located at the lower bound of the defined search spaces for all three scenarios. Even though Scenario 1 and Scenario 2 of PV-Diesel case showcased better performance relative to the Battery-Diesel case, they accounted for high economic costs with respect to the base operation.

With increasing renewable penetration levels, the associate performance of this hybrid topology further got deteriorated as presented in Table 12. It was also observed that in high penetration levels this investment results in lower operating costs than the base case system. However, those reductions were inadequate to recover the high capital costs associated with PV installation. Thus, this topology was also considered unsatisfactory in achieving the stated objectives.

\section{PV-Diesel-Battery Case}

The three scenarios defined in the PV-Diesel case were considered again with the addition of storage. The incorporated search-space for each scenario is given in Table 13 and the results for the optimum system configurations are presented in Table 14.

For Scenario 1, the optimum PV array and converter size was located near the lower limit of the given search space. Even with the addition of storage only a small benefit was achieved within this penetration level. PV arrays were optimally sized around the upper limit for Scenario 2 and in the middle range for Scenario 3. The battery storage also showed an elevated usage. Converter sizes were optimally located at higher values to facilitate the battery operation as well as the increased solar penetration. So, at increased penetration levels, when integrated with storage, the lower operating costs associated with renewables have gained the maximum advantage when deciding the optimum system configuration. Converter size has also played a decisive task by facilitating the bidirectional energy transfer occurring between AC/DC buses.

As presented in Table 15, PV-Diesel-Battery topology has performed considerably well in the economic paradigm among the suggested topologies. Scenario 1 gave improved LCOE and NPC compared to PV-Diesel case. However, extrinsic economic parameters suggested no enhancement of associate performance compared to the base case. When increasing the penetration level and storage capacity, the PV-Diesel-Battery topology gained gradual enhancement in its associate economic performance with the base-case. Among the three scenarios, Scenario 3 accounted for the lowest LCOE with $0.5 \%$ reduction to that of the diesel-only operation. Conducted technology assessments for the diesel generators, solar PV and battery storage are presented in Tables 16, 17 and 18 respectively.

In low PV penetration levels, the LF dispatch strategy was selected to be more economical. So, the battery storage was mainly deployed in optimizing the solar PV penetration by
Table 15 Economic analysis for PV-Diesel-Battery case

\begin{tabular}{lllll}
\hline & Base Case & Scenario 1 & Scenario 2 & Scenario 3 \\
\hline LCOE (CAD/kWh) & 0.5146 & 0.5158 & 0.5235 & 0.5121 \\
NPC (CAD) & $21,314,090$ & $21,364,520$ & $21,682,110$ & $21,212,200$ \\
Return on investment (\%) & - & 0.4 & 1.8 & 2.8 \\
IRR (\%) & - & 1.9 & 2.9 & 4.1 \\
Simple payback time $(\mathrm{yr})$ & - & 18.03 & 18.5 & 16 \\
\hline
\end{tabular}


Table 16 Technology assessment of diesel generators for 20 years

\begin{tabular}{llllll}
\hline Diesel Generators & & Base Case & Scenario 1 & Scenario 2 & Scenario 3 \\
\hline Energy production $(\mathrm{kWh})$ & $400 \mathrm{~kW}$ & $20,267,925$ & $20,515,388$ & $39,963,909$ & $35,046,194$ \\
& $800 \mathrm{~kW}$ & $41,859,861$ & $40,990,873$ & $13,863,217$ & $14,194,059$ \\
Fuel Consumption & $400 \mathrm{~kW}$ & $5,785,709$ & $5,860,016$ & $10,921,679$ & $9,517,239$ \\
(Litres) & $800 \mathrm{~kW}$ & $11,010,922$ & $10,797,688$ & $3,532,328$ & $3,577,926$ \\
Capacity Factor & $400 \mathrm{~kW}$ & 28.92 & 29.27 & 57.02 & 50 \\
$(\%)$ & $800 \mathrm{~kW}$ & 29.86 & 29.24 & 9.89 & 10.12 \\
Mean electrical efficiency (\%) & $400 \mathrm{~kW}$ & 35.62 & 35.60 & 37.18 & 37.42 \\
& $800 \mathrm{~kW}$ & 38.50 & 38.44 & 39.89 & 40.43 \\
\hline
\end{tabular}

increasing the co-relation between the load and the intermittent source. CC dispatch strategy was selected for the last two scenarios where both renewable generation and the diesel generators were used to charge the batteries. While extracting the excess renewable capacity, this control strategy forced the diesel generators to operate near their optimum efficiency. This is evidently shown by the gradual increase of mean electric efficiencies of the diesel generators in Table 16. Figure 7 shows the impact of solar PV and battery integration on the annual diesel electricity production for Scenario 3. With PV and battery integration, $400 \mathrm{~kW}$ generator gained the major share of energy delivery as opposed to the variations seen in Base case (Fig. 6). This further guarantees the optimum operation of the diesel generators given the prevailing lower demand. The associated environmental benefits of high renewable penetration and optimized diesel operation is evident from the emission analysis given in Table 19 for the 20 years project lifetime. As estimated by HOMER model, the gradual reduction of greenhouse gas emissions in each scenario compared to the Base-Case operation heightens the environmental performance associated with the PV-Diesel-Battery topology.

Based on the overall analysis it was observed that with topologies like PV-Diesel and Diesel-Battery the envisioned benefits of HRES could not be maximized for this off-grid power system. However, PV-Diesel-Battery topology as suggested in Scenario 3 would be a favourable retrofit to the existing diesel-facility. For a renewable fraction of $21 \%$, expected fuel savings are estimated to be around $22 \%$ with respect to the existing configuration. Figure 8 shows a comparison of $\mathrm{CO}_{2}$ emissions between Base case and Scenario 3 throughout the project lifetime.

Table 17 Technology assessment of Solar PV for 20 years

\begin{tabular}{llll}
\hline Solar - PV & Scenario 1 & Scenario 2 & Scenario 3 \\
\hline Rated capacity $(\mathrm{kW})$ & 25 & 400 & 625 \\
Energy production $(\mathrm{kWh})$ & 645,352 & $10,325,645$ & $16,133,820$ \\
Capacity factor $(\%)$ & 14.7 & 14.7 & 14.7 \\
PV penetration (\%) & 1.05 & 16.85 & 26.33 \\
\hline
\end{tabular}

It must be noted that this optimization process was primarily driven as a cost problem and externalities like environmental and legislative regulations were not directly accounted other than the carbon penalty price. It also excludes costs incurred due to spillage and emissions during the fuel transportation as well as soil and ground-water contamination occurring inside diesel storage facilities. In a study done in 1996 [34], it was estimated that the cost of environmental degradation (emissions and spills) due to diesel engine facilities to be $\$ 0.80$ per litre. In the present context, a detailed analysis of cost relations to several environmental impacts is necessary to determine a descriptive environmental degradation value for the considered diesel facility. Such analysis is beyond the scope of this paper. However, if those indirect costs were to be accounted, the actual performance of the proposed HRES configuration would be much greater than that determined through this analysis. Also, with projected cost reductions in solar PV arrays, batteries and converters, incorporation of renewable alternatives in off-grid power systems will gain increased momentum.

The proven benefits of hybrid power systems can be further evaluated if the optimization process incorporated scenarios with increasing renewable penetration and decreasing fossil fuel-based generation. However, this will eventually cause concerns regarding the energy security of the community. Also, increasing levels of renewable penetration into smaller and weaker off-grid systems can induce power system stability violations. However, the optimization of the grid configuration does not solely indicate that the selected system would perfectly match the expectations of the power system planner. Thus, the optimization step must be followed with series of steady state and transient stability analysis to confirm whether

Table 18 Technology assessment of battery storage for 20 years

\begin{tabular}{llll}
\hline Battery & Scenario 1 & Scenario 2 & Scenario 3 \\
\hline No of units & 10 & 110 & 120 \\
Nominal capacity (kWh) & 76 & 836 & 912 \\
Throughput (kWh) & 4377 & $8,598,825$ & $10,305,986$ \\
Autonomy (hrs) & 0.217 & 2.4 & 2.6 \\
\hline
\end{tabular}




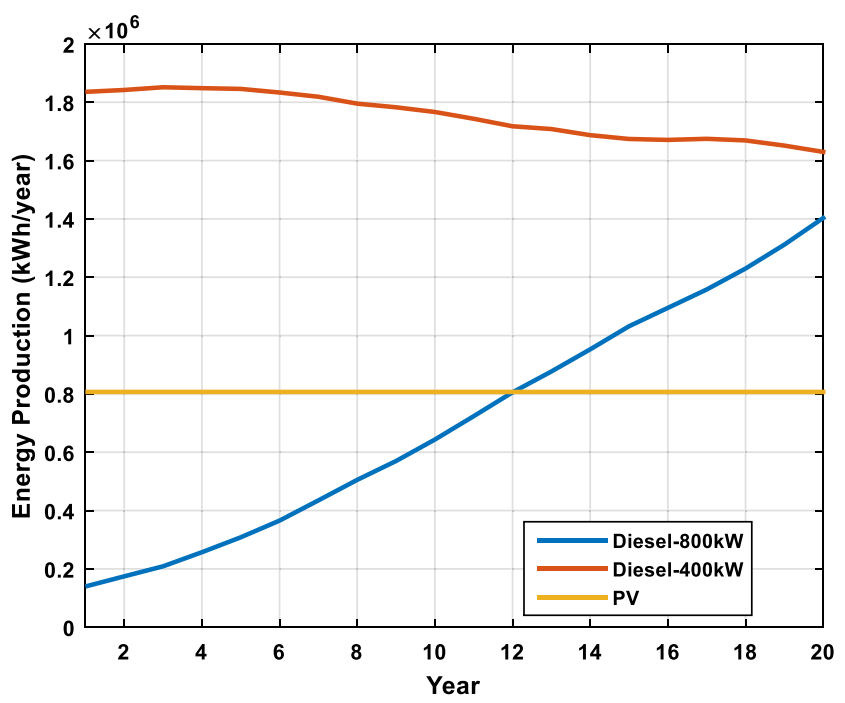

Fig. 7 Contribution for energy production for scenario 3

the selected optimum system meets the standard grid codes and the stability criteria [26].

\section{Conclusion}

This paper presents an optimization study and a techno economic analysis conducted based on a hypothetical off-grid power system in Northern Canada. Battery-Diesel, PVDiesel and PV-Diesel-Battery configurations were examined to find the optimum retrofit for the current diesel-based facility, while incorporating gradually increasing renewable penetration scenarios for the latter two types. The screening process that considered thirteen impact factors concluded that Liion batteries to be the best battery type for this application. HOMER software platform was used to carry out the analysis and optimization with some user intervention to incorporate the load growth and diesel fuel price escalation.

Initial analysis showed that Diesel-Battery only and DieselPV only configurations do not provide satisfactory return on investment and environmental performance. In contrast,

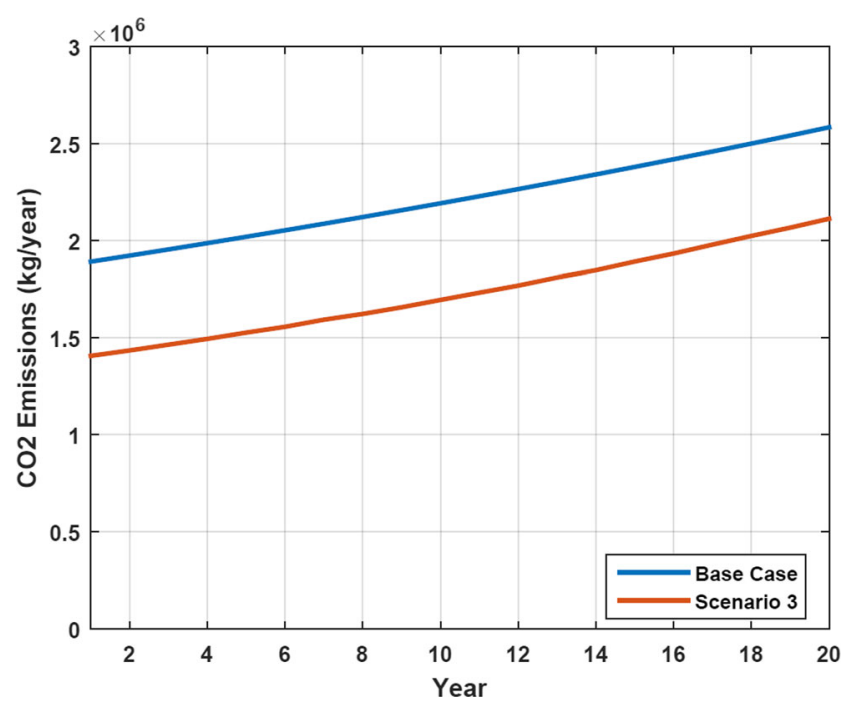

Fig. $8 \mathrm{CO}_{2}$ emissions

significant maximization of environmental benefits was identified at high solar penetration levels and increased battery and converter capacities in the PV-Diesel-Battery case. When the renewable fraction is increased to $21 \%$, fuel savings around $22 \%$ could be achieved. Under this scenario, the LCOE remained comparable to the base case despite high capital investments. Extrinsic economic indices assessing the economic performance of the selected HRES related to the base case system also predicted positive return, although at somewhat lower rates. This observation is primarily influenced by the elevated capital costs associated with renewable integration at the selected remote location. This inherent feature prevailing in the Northern off-grid power systems makes it considerably hard to economically compete with the existing diesel generation at low renewable penetration levels; and lowers the economic benefits achievable at high penetration levels.

Although the cost of producing electricity is deemed to be the fundamental attribute of energy planning, the results obtained through this study must be analysed within the scope of economic, environmental, reliability, energy security and legislative aspects to arrive at more realistic rationale. When all
Table 19 Emission analysis for 20 years

\begin{tabular}{lllll}
\hline Emission Category & \multicolumn{2}{l}{ Annual Emissions (kg for 20 years) } \\
\cline { 2 - 5 } & Base-case & \multicolumn{2}{l}{ Proposed PV-Diesel-Battery Hybrid System } \\
\cline { 3 - 5 } & & Scenario 1 & Scenario 2 & Scenario 3 \\
\hline Carbon Dioxide & $44,396,579$ & $44,029,367$ & $38,204,595$ & $34,612,925$ \\
Carbon Monoxide & 27,091 & 26,867 & 23,313 & 21,121 \\
Unburned Hydrocarbons & 774 & 767 & 666 & 603 \\
Particulate Matter & 2554 & 2533 & 2198 & 1991 \\
Sulfur Dioxide & 107,755 & 106,864 & 92,727 & 84,009 \\
Nitrogen Oxides & 430,368 & 426,808 & 370,345 & 335,528 \\
\hline
\end{tabular}


these factors are considered it can be argued that the PVDiesel-Battery hybrid topology to be a sound investment choice for the Northern off-grid power systems. Incidents of unpredictable weather patterns that hinder the construction and use of winter roads is becoming more frequent due to climate change, directly affecting the fuel supply for diesel generation. Therefore, diversification of the energy mix enhances the reliability and energy security of this remote power system. Pertaining to the historic price trend of fossil fuel resources, diesel prices have shown a rapid rise whenever subjected to increased demand, overwhelming resource extraction and transportation issues in these remote off-grid settlements. So, having the option of on-demand renewable power by means of PV and battery bolster the ability of this power system to respond towards volatile and unpredictable market price fluctuations. Also, considering various environmental costs associated with the operation and maintenance of a diesel facility, the precipitated need of integrating renewable generation get further heightened. Both solar PV and Li-ion batteries are considered environmentally safe and poses no risks of greenhouse gas emissions. So, adaptation of this HRES topology would certainly drive this community towards sustainable energy development.

Acknowlegements The authors would like to thank NSERC CREATE: Sustainable Engineering in Remote Areas (SERA) program and University of Manitoba for funding the project.

Publisher's Note Springer Nature remains neutral with regard to jurisdictional claims in published maps and institutional affiliations.

\section{References}

1. Akhil, Abbas A et al. (2015). "SANDIA REPORT DOE / EPRI electricity storage handbook in collaboration with NRECA."

2. Arriaga M, Canizares CA, Kazerani M (2014) Northern lights: access to Electricity in Canada's northern and remote communities. IEEE Power and Energy Magazine 12(4):50-59

3. Beaudin M, Zareipour H, Schellenberg A, Rosehart W (2014) Energy storage for mitigating the variability of renewable electricity sources. Energy Storage for Smart Grids: Planning and Operation for Renewable and Variable Energy Resources (VERs) 14(4):1-33. https://doi.org/10.1016/j.esd.2010.09.007

4. Bhattarai PR, Thompson S (2016) Optimizing an off-grid electrical system in Brochet, Manitoba, Canada. Renew Sust Energ Rev 53: 709-719. https://doi.org/10.1016/j.rser.2015.09.001

5. "Canadian Off Grid Utilities Association - Manitoba Hydro." http:// www.cogua.ca/history/manitoba_systems.htm (December 18, 2017)

6. "Carbon Tax Scheme - Manitoba - CBC News." http://www.cbc.ca/ news/canada/manitoba/climate-change-carbon-pricing-manitoba- 1 . 4375005 (January 14, 2018)

7. Chu S, Cui Y, Liu N (2016) The path towards sustainable energy. Nat Mater 16(1):16-22. https://doi.org/10.1038/nmat4834

8. Diouf B, Pode R (2015) Potential of Lithium-ion batteries in renewable energy. Renew Energy 76:375-380. https://doi.org/10.1016/j. renene.2014.11.058
9. Ferreira HL et al (2013) Characterisation of electrical energy storage technologies. Energy 53:288-298. https://doi.org/10.1016/j. energy.2013.02.037

10. Gilman, Paul, and Peter Lilienthal. (2006). "Micropower system modeling." : 379-418

11. Hesse, Holger C., Michael Schimpe, Daniel Kucevic, and Andreas Jossen. (2017). 10 energies Lithium-Ion Battery Storage for the Grid - A Review of Stationary Battery Storage System Design Tailored for Applications in Modern Power Grids

12. HOMER-Pro. "Homer Pro 3.12 - User Manual." https://www. homerenergy.com/products/pro/docs/3.12/how homer calculates the_pv_array_power_output.html (November 17, 2018)

13. HOMER Pro. "HOMER Pro Multi-Year Module." https://www. homerenergy.com/products/pro/modules/multi-year.html (November 22, 2018)

14. Hooshangi, H.R. (2014). "Feasibility study of wind-diesel hybrid power system for remote communities in north of Quebec." (February)

15. Hu, Xiaosong, Changfu Zou, Caiping Zhang, and Yang Li. (2017). "Technologcal Developments in Batteries: A Survey of Principal Roles, Types, and Management Needs." IEEE Power and Energy Magazine 15(5):20-31

16. Ibrahim $\mathrm{H}$ et al (2012) Wind-diesel hybrid system : energy storage system selection method. The 12th International Conference on Energy Storage: 1-10

17. Ibrahim H, Ilinca A, Perron J (2007) Comparison and analysis of different energy storage techniques based on their performance index. IEEE Canada Electrical Power Conference:393-398 http:// ieeexplore.ieee.org/document/4520364/

18. "Indigenous and Northern Affairs Canada." https://www.aadncaandc.gc.ca/eng/1314295992771/1314296121126 (December 18, 2017)

19. Isherwood W et al (2000) Remote power systems with advanced storage Technologies for Alaskan Villages. Energy 25(10):10051020

20. Jenkins, Nicholas, J. B. Ekanayake, and Goran Strbac. (2010). Institution of Engineering and Technology Distributed Generation

21. Khan MJ, Iqbal MT (2005) Pre-feasibility study of stand-alone hybrid energy Systems for Applications in Newfoundland. Renew Energy 30(6):835-854

22. Lan $\mathrm{H}$ et al (2015) Optimal sizing of hybrid PV/diesel/battery in ship power system. Appl Energy 158:26-34. https://doi.org/10. 1016/j.apenergy.2015.08.031

23. Ling-Chin J, Roskilly AP (2016) Investigating the implications of a new-build hybrid power system for roll-on/roll-off cargo ships from a sustainability perspective - a life cycle assessment case study. Appl Energy 181:416-434. https://doi.org/10.1016/j.apenergy. 2016.08.065

24. Luna-Rubio R, Trejo-Perea M, Vargas-Vázquez D, Ríos-Moreno GJ (2012) Optimal sizing of renewable hybrids energy systems: a review of methodologies. Sol Energy 86(4):1077-1088

25. Ma T, Yang H, Lu L (2014) A feasibility study of a stand-alone hybrid solar-wind-battery system for a Remote Island. Appl Energy 121:149-158. https://doi.org/10.1016/j.apenergy.2014.01.090

26. Manitoba Hydro. (2008). "Recommendations for Reducing or Eliminating the Use of Diesel Fuel to Supply Power in Off-Grid Communities.” http://www.hydro.mb.ca/regulatory_affairs/ electric/gra_2010_2012/Appendix_13_9.pdf

27. Masters, Gilbert $\bar{M}$. (2004). Renewable and efficient electric power systems. doi: https://doi.org/10.1002/0471668826

28. Mizani S, Yazdani A (2009) Design and operation of a remote microgrid. IECON Proceedings (Industrial Electronics Conference) (2):4299-4304

29. Mohammed YS, Mustafa MW, Bashir N (2014) Hybrid renewable energy Systems for off-Grid Electric Power: review of substantial 
issues. Renew Sust Energ Rev 35:527-539. https://doi.org/10. 1016/j.rser.2014.04.022

30. Nitta, Naoki, Feixiang Wu, Jung Tae Lee, and Gleb Yushin. (2015) "Li-Ion Battery Materials: Present and Future." Materials Today 18(5):252-64. https://doi.org/10.1016/j.mattod.2014.10.040

31. Okoye CO, Solyalı O (2017) Optimal sizing of stand-alone photovoltaic Systems in Residential Buildings. Energy 126: 573-584

32. Pelland S, Turcotte D, Colgate G, Swingler A (2012) Nemiah Valley photovoltaic-diesel mini-grid: system performance and fuel saving based on one year of monitored data. IEEE Transactions on Sustainable Energy 3(1):167-175

33. Rahman MM et al (2016) A hybrid renewable energy system for a north American off-grid community. Energy 97:151-160

34. Chapman RN (1996) Hybrid power Technology for Remote Military Facilities. In Proceedings of Power Quality Solutions/ Alternative Energy:415-427

35. Schaber C, Mazza P, Hammerschlag R (2004) Utility-scale storage of renewable energy. Electr J 17(6):21-29

36. Siddaiah R, Saini RP (2016) A review on planning, configurations, modeling and optimization techniques of hybrid renewable energy systems for off grid applications. Renew Sust Energ Rev 58:376396. https://doi.org/10.1016/j.rser.2015.12.281

37. Stroe D-i et al (2017) Operation of a Grid-Connected Lithium-Ion Battery Energy Storage System for Primary Frequency Regulation: A Battery Lifetime Perspective. 53(1):430-438
38. Tervo E et al (2018) An economic analysis of residential photovoltaic systems with Lithium ion battery storage in the United States. Renew Sust Energ Rev 94(May):1057-1066

39. Thomas D, Deblecker O, Ioakimidis CS (2016) Optimal design and techno-economic analysis of an autonomous small isolated microgrid aiming at high RES penetration. Energy 116:364-379. https://doi.org/10.1016/j.energy.2016.09.119

40. Thompson S, Duggirala B (2009) The feasibility of renewable energies at an off-grid Community in Canada. Renew Sust Energ Rev 13(9):2740-2745

41. A Grant Thornton and Clean Energy. (2018). "Renewable energy discount rate survey results - 2017." (January)

42. Wen S et al (2016) Allocation of ESS by interval optimization method considering impact of ship swinging on hybrid PV/diesel ship power system. Appl Energy 175:158-167. https://doi.org/10. 1016/j.apenergy.2016.05.003

43. Wu X, Xiaosong H, Yin X et al (2017a) Optimal battery sizing of smart home via convex programming. Energy 140:444-453. https://doi.org/10.1016/j.energy.2017.08.097

44. Wu X, Xiaosong H, Teng Y et al (2017b) Optimal integration of a hybrid solar-battery power source into smart home Nanogrid with plug-in electric vehicle. J Power Sources 363:277-283. https://doi. org/10.1016/j.jpowsour.2017.07.086

45. Yekini Suberu M, Wazir Mustafa M, Bashir N (2014) Energy storage Systems for Renewable Energy Power Sector Integration and Mitigation of intermittency. Renew Sust Energ Rev 35:499-514. https://doi.org/10.1016/j.rser.2014.04.009 